\title{
RANCANG BANGUN SISTEM LAPORAN DAYA SERAP (SILADARA) BERBASIS WEB PADA BADAN PUSAT STATISTIK KABUPATEN SUKABUMI
}

\author{
Farhan Rasyad Koswara ${ }^{1}$ \\ ${ }^{1}$ Program Studi Teknik Informatika, Fakultas Teknologi dan Informasi, \\ Universitas Nusa Putra Sukabumi, Indonesia \\ ${ }^{1}$ Farhan.rasyad01@gmail.com
}

\begin{abstract}
ABSTRAK
Laporan adalah bentuk penyajian fakta tentang suatu keadaan atau kegiatan. Organisasi membutuhkan suatu cara bagaimana membuat laporan dengan cepat dan mudah. Aplikasi spreadsheet merupakan salah satu sistem yang memudahkan dalam penulisan laporan, hanya saja untuk menggunakan sistem ini dibutuhkan sebuah keahlian dan keterampilan. Sistem pelaporan Berbentuk web merupakan salah satu cara untuk menyelesaikan masalah penulisan Laporan, karena lebih cepat dan mudah digunakan serta hanya membutuhkan internet untuk mengakses sistem atau aplikasi tersebut. Metode yang digunakan dalam membangun sistem ini ialah mengunakan metode Prototype. Menggunakan Codeigniter dan Php sebagai framework dan Mysql untuk database. Sistem laporan daya serap (Siladara) ini merupakan suatu aplikasi web berbentuk Prototype yang berisi laporan anggaran dan kwitansi di BPS Kabupaten Sukabumi.
\end{abstract}

Kata Kunci— Laporan, Organisasi, Sistem, Siladara, Web.

\begin{abstract}
A report is a form of presenting facts about a situation or activity. Organizations need a way of how to make a reports quickly and easily.The spread sheet application is a system or application that make it easy to write reports, it's just that to use this system requires expertise and skills. The web-shaped reporting system is one way to solve the problem of writing report, because it is faster and easier to use and only requires the internet to access the system or application. The method used in building this system is to use the prototype method. Using Codeigniter and Php as framework and Mysql for the database. This absorption capacity report system (siladara) is a prototype web application containing budget reports and receipts at BPS Sukabumi Regency.
\end{abstract}

Keywords—Report, Organization, System, Siladara, Web. 


\section{PENDAHULUAN}

Laporan adalah bentuk penyajian fakta tentang suatu keadaan atau kegiatan. Laporan bisa berbentuk lisan maupun tulisan. Fungsi dari laporan ini biasanya digunakan untuk menyimpan informasi berupa informasi keuangan, informasi kegiatan, informasi suatu keadaan, dll. Di suatu organisasi, laporan sangat dibutuhkan sebagai bahan evaluasi dan interaksi. Sistem aplikasi spreadsheet seperti Microsoft excel merupakan salah satu aplikasi yang digunakan untuk menulis laporan, namun kelemahan dari Sistem ini yakni aplikasi ini memakan banyak tempat dan membutuhkan keahlian untuk digunakan dalam menulis laporan.

Sistem pelaporan basis web merupakan salah satu solusi dalam menyelesaikan masalah penulisan laporan. Karena kelebihan dari sistem berbasis web adalah tidak memakan tempat, mudah digunakan (praktis), dan hanya membutuhkan jaringan internet untuk mengaksesnya. BPS Kabupaten sukabumi merupakan salah satu organisasi yang masih menggunakan sistem berbasis spreadsheet seperti Microsoft excel. Sehingga penulisan laporan anggaran dan kwitansi masih menggunakan sistem aplikasi spreadsheet. Diketahui bahwa aplikasi spreadsheet atau yang lebih dikenal dengan Microsoft excel, kurang efektif untuk digunakan dalam penulisan laporan di bagian anggaran dan data kwitansi.

Penelitian ini bertujuan untuk merancang dan membangun suatu sistem yang mana dapat membantu dalam penulisan laporan di bagian anggaran dan kwitansi di BPS Sukabumi. Menggunakan codeigniter sebagai framework dan mysql sebagai databasenya dan data - data yang di dapat oleh penulis di BPS Kabupaten sukabumi saat bulan agustus 2020. Diharapkan hal ini dapat membantu organisasi dalam penulisan laporan di bagian anggaran dan data kwitansi. Di penelitian ini penulis memilih judul, yaitu "Rancang bangun sistem laporan daya serap (SILADARA) di BPS Kabupaten Sukabumi”. Karena sesuai dengan latar belakang yang di dapat.

\section{TINJAUAN PUSTAKA}

\subsection{Tinjauan Pustaka}

Sistem adalah suatu elemen yang saling terhubung dan memiliki tujuan tertentu. Sistem bisa dikatakan sebagai alat, karena sistem merupakan sebuah alat yang digunakan untuk mencapai tujuan tertentu. Manusia merupakan salah satu contoh dari sistem.

Web Browser adalah aplikasi perangkat lunak yang digunakan untuk mengambil dan menyajikan sumber infromasi web [1]. Di dalam Web browser terdapat URI (Uniform Resource Identifier), URI adalah sumber informasi web yang terdiri dari halaman web, video, gambar, dan konten lainnya. Google Chrome merupakan salah satu contoh dari Web Browser.

Web Server adalah sebuah perangkat lunak server yang berfungsi menerima permintaan HTTP atau HTTPS dari klien yang dikenal dengan Web Browser dan mengirimkan kembali hasilnya dalam bentuk halaman - halaman web yang umumnya berbentuk dokumen HTML [2].

PHP (Personal Home Page) adalah pemograman interpreter yaitu proses penerjemahan baris kode sumber menjadi kode mesin yang dimengerti computer secara langsung pada saat baris kode dijalankan. PHP (Personal Home Page) disebut sebagai pemograman Server side Programming, hal ini dikarenakan seluruh prosesnya dijalankan pada server. PHP (Personal Home Page) adalah suatu Bahasa pemograman yang memiliki hak cipta terbuka atau yang juga dikenal dengan istilah Open Source, yaitu pengguna dapat mengembangkan kode - kode - kode fungsi PHP (Personal Home Page) sesuai dengan kebutuhannya [3].

Codeigniter adalah salah satu framework PHP yang bersifat open source. Codeigniter dirancang oleh EllisLab kemudian dikembangkan oleh British Columbia Instittute of Technology. Codeigniter pertama kali dirilis pada tanggal 26 februari 2006 dan sampai saat ini telah dikembangkan hingga ke versi 3.1.10 pada beberapa bulan baru.pengembangan framework ini akan terus berjalan dan direncanakan akan segera rilis versi ke 4 nya [4].

Codeigniter merupakan salah satu framework yang menggunakan konsep MVC (Model, View, Controller). Kelebihan dari konsep ini ialah, antara lain:

- Koneksi database mudah untuk dilakukan.

- $\quad$ Konsep MVC meningkatkan fleksibilitas, pemeliharaan dan skalabilitas.

- Komponen yang ada berfungsi secara independen antara satu sama lain.

MySQL merupakan sebuah program database server yang mampu menerima dan mengirimkan datanya dengan sangat cepat, multiuser serta menggunakan perintah standar SQL (Structured Query Languange) [5]. Kelebihan dari MySQL ini ialah bersifat terbuka atau Open Source.

Javascript Object Notation (JSON) adalah format pertukaran data yang ringan, mudah dibaca dan ditulis, serta mudah diterjemahkan dan dibuat (generate). Format ini dibuat berdasarkan bagian dari Bahasa Pemrograman JavaScript. JSON merupakan format teks yang tidak tergantung pada bahasa pemrograman apapun karena menggunakan bahasa yang umum digunakan oleh programmer. Oleh karena itu sifat-sifat tersebut, JSON ideal sebagai bahasa pertukaran data. JSON memiliki beberapa kelebihan dibandingkan dengan XML, kelebihan-kelebihan antara lain: (1) Format penulisan JSON relatif lebih terstruktur dan mudah; (2) Ukuran karakter yang dibutuhkan JSON lebih kecil dibandingkan XML untuk data yang sama sehingga kecepatan pertukaran data JSON lebih unggul dibandingkan XML; (3) Proses browser parsing JSON lebih sederhana dibandingkan pada XML karena JSON 
menggunakan function JavaScript eval() untuk melakukan parsing sedangkan dokumen XML diparsing oleh XML HttpRequest [6].

\section{METODE YANG DIUSULKAN}

Penelitian ini dilakukan dan diselesaikan melalui 4 tahapan penelitian yaitu: (1) pengumpulan data dan analisis data; (2) desain perancangan sistem; (3) membangun sistem dan uji sistem; dan (4) penulisan laporan hasil penelitian. Tahapan - tahapan yang dilakukan dalam penelitian ini dapat dilihat pada Gambar 1.

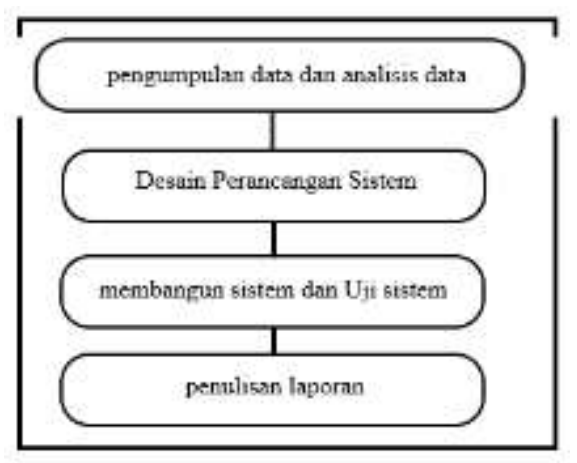

Gambar 1. Tahapan Penelitian

Tahap pertama yang dilakukan adalah pengumpulan data - data dan menganalisis data yang dibutuhkan dalam membangun sistem. Pada tahap ini metode yang dilakukan yaitu wawancara dan studi literatur. Wawancara dilakukan dengan Staf Tu BPS Kabupaten Sukabumi. Data yang didapatkan pada penelitian ini berupa data anggaran setiap kegiatan dan data yang diambil melalui studi literatur merupakan data yang membahas perihal web serta contohcontoh penulisan jurnal. Data yang didapat lalu dianalisis, sehingga dapat ditemukan hal yang dibutuhkan sistem.

Tahap kedua adalah tahap dimana penulis melakukan desain perancangan sistem. Perancangan sistem menggunakan Unified Modeling Language (UML) dan perancangan database menggunakan Mysql. Unified Modeling Language (UML) merupakan sebuah standar dalam industri dengan tujuan untuk merancang, visualisasi dan mendokumentasikan suatu sistem perangkat lunak. UML memberikan tawaran akan sebuah standar untuk merancang model sebuah sistem. UML dapat digunakan untuk pemodelan pada semua jenis aplikasi piranti lunak, di mana aplikasi tersebut dapat berjalan pada piranti keras, dalam jaringan dan sistem operasi apapun, serta dapat ditulis dalam bahasa pemrograman apapun [7].

Tahap ketiga adalah tahap membangun dan pengujian sistem. Membangun sistem Menggunakan framework Codeigniter dan Bootstrap. Metode yang digunakan dalam membangun sistem aplikasi adalah metode Prototype. Prototype merupakan metode yang dikembangkan dengan berkomunikasi kepada client agar aplikasi yang dihasilkan sesuai dengan keinginan client [8].

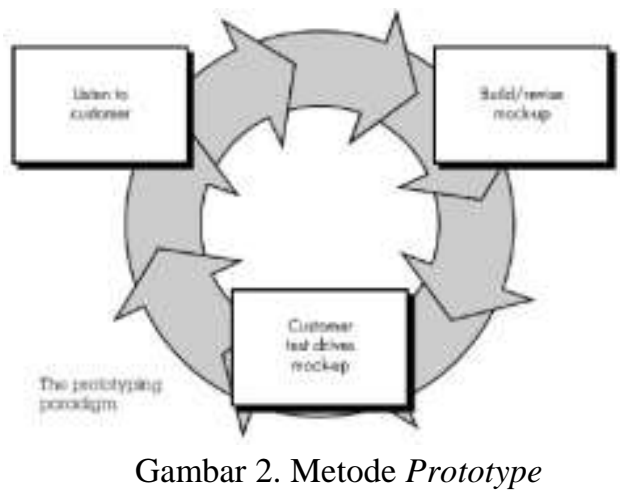

Pengujian aplikasi dilakukan dengan menggunakan pengujian alfa serta analisis hasil pengujian sistem. Pengujian alfa merupakan pengujian yang dilakukan pada sisi pengembang [8]. Dalam kasus ini pengujian alfa dilakukan menggunakan teknik black box testing yang dapat didefinisikan suatu pengujian untuk mengetahui apakah semua perangkat lunak yang terdapat pada sistem telah berjalan dengan semestinya sesuai dengan kebutuhan fungsional yang didefinisikan. Pengujian beta adalah pengujian yang dilakukan oleh user untuk menguji apakah aplikasi sudah sesuai atau belum terhadap keinginan user [9].

Tahap keempat adalah tahap terakhir dan merupakan tahap dimana dilakukan penulisan laporan hasil penelitian. Tahap ini berisi dokumentasi proses dari tahap awal sampai tahap akhir. Laporan hasil penelitian ditulis dalam bentuk tulisan ilmiah.

\section{HASIL PENELITIAN}

Setelah Penelitian dilaksanakan, berikut adalah bagian hasil dan pembahasan dari penelitian yang telah dilaksanakan.

\subsection{Analisis sistem}

Analisis sistem bertujuan untuk mempelajari, menganalisis masalah dan memahami sistem yang ada sesuai dengan tujuan yang ingin dicapai. Berdasarkan hasil pengamatan dan analisis yang dilakukan diketahui bahwa sistem yang sedang berjalan saat ini pada BPS Kabupaten Sukabumi masih menggunakan aplikasi spreadsheet dalam penulisan laporan di bagian data anggaran dan data kwitansi. Sehingga penulisan laporan di organisasi tersebut bisa dibilang belum maksimal.

\subsection{Rancangan Sistem}

Model UML (Unified Modeling Language) yang digunakan dalam penelitian ini terdiri dari activity diagram, dan usecase diagram.

\subsubsection{Activity Diagram Data List}




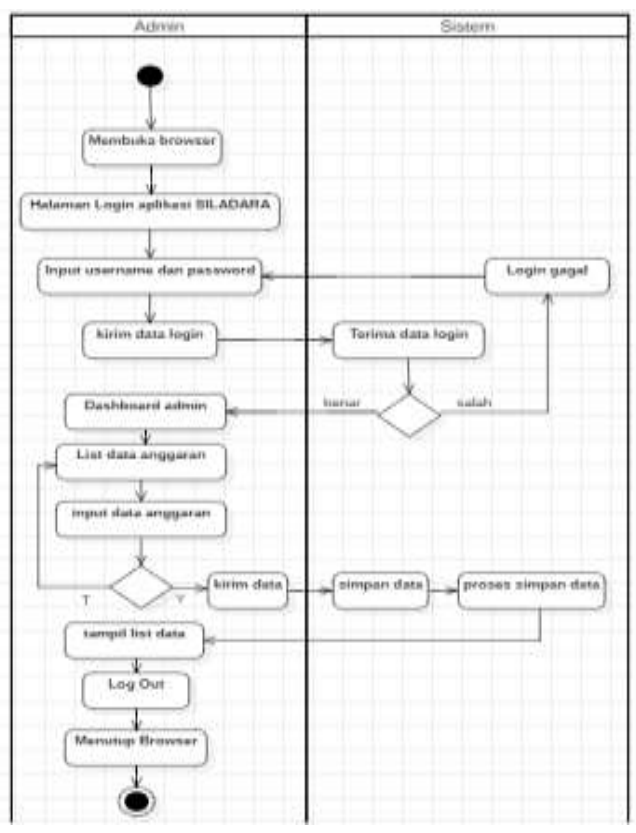

Gambar 3

Activity Diagram Data list

\subsubsection{Activity Diagram Data Kwitansi}

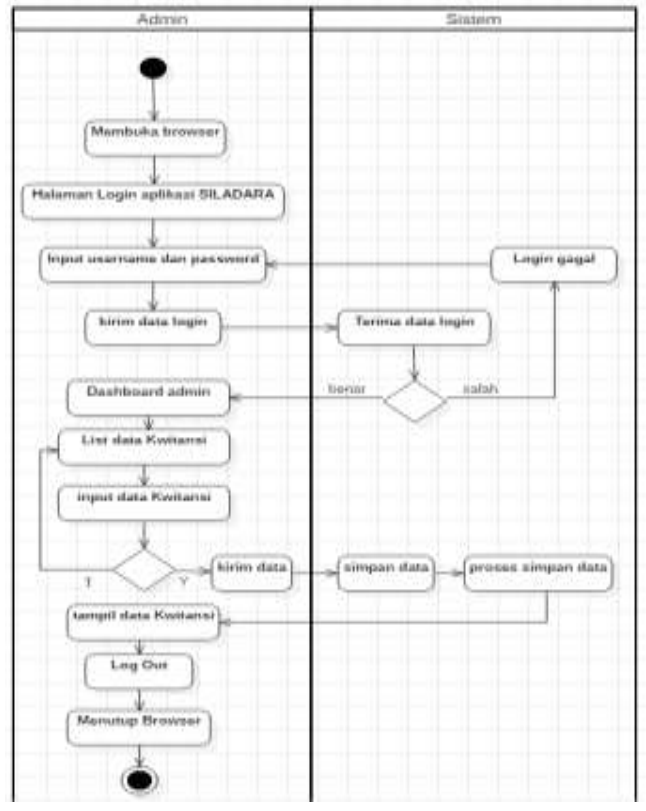

Gambar 4

Activity Diagram Data Kwitansi

\subsubsection{Usecase Diagram}

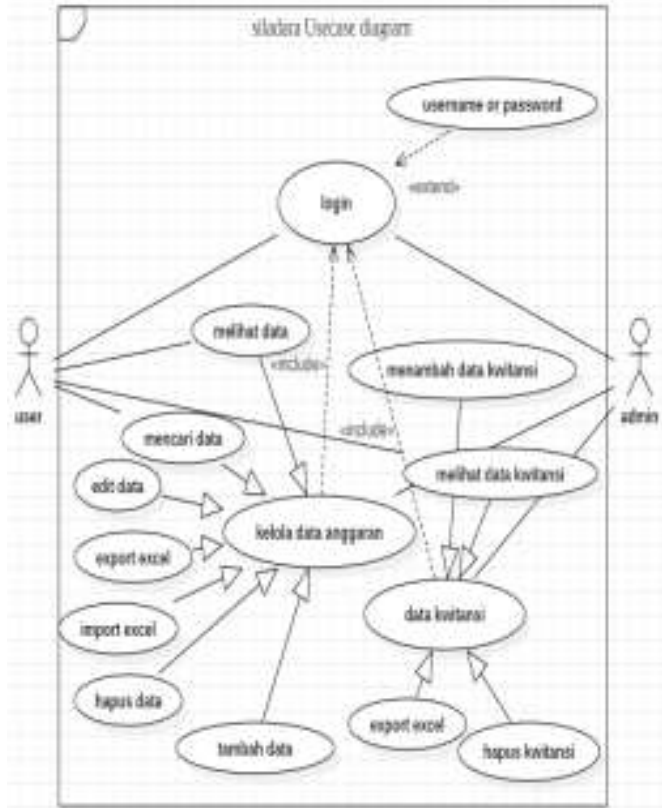

Gambar 5

Usecase Diagram Sistem Laporan daya serap

\subsection{Rancangan Tampilan Website}

Bagian rancangan tampilan website merupakan bagian tampilan dari hasil perancangan sistem yang dibangun. Termasuk dengan penjelasan dan fungsinya.

\subsubsection{Halaman Login}

Halaman ini merupakan halaman awal, dan pengguna diharuskan untuk mengisi username dan password agar bisa masuk ke sistem atau aplikasi ini.

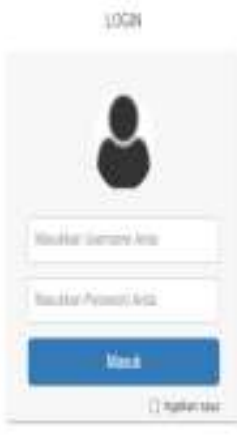

Gambar 6

Halaman Login

\subsubsection{Halaman Dashboard}

Halaman ini merupakan Halaman utama atau halaman depan di sistem atau aplikasi siladara (Sistem Laporan daya Serap) ini. 


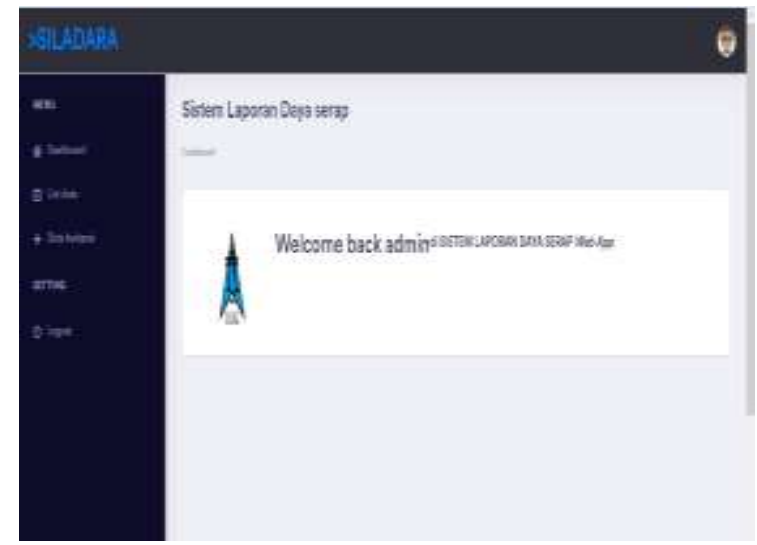

Gambar 7

Halaman Dashboard

\subsubsection{Halaman List Data}

Halaman ini adalah halaman dimana tempat data list berada. Berisi data kegiatan beserta dengan anggarannya masing - masing.

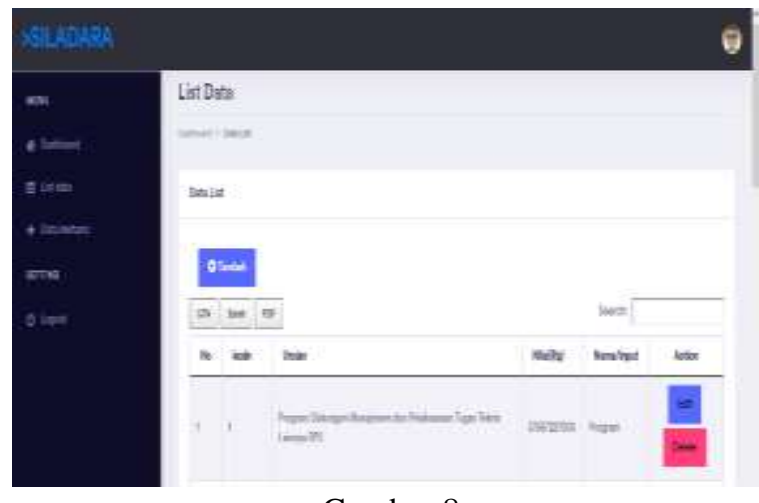

Gambar 8

Halaman List Data

\subsubsection{Halaman Data Kwitansi}

Halaman ini adalah halaman yang berfungsi sebagai tempat data kwitansi disimpan. Memiliki fungsi mencatat atau menyimpan data kwitansi.

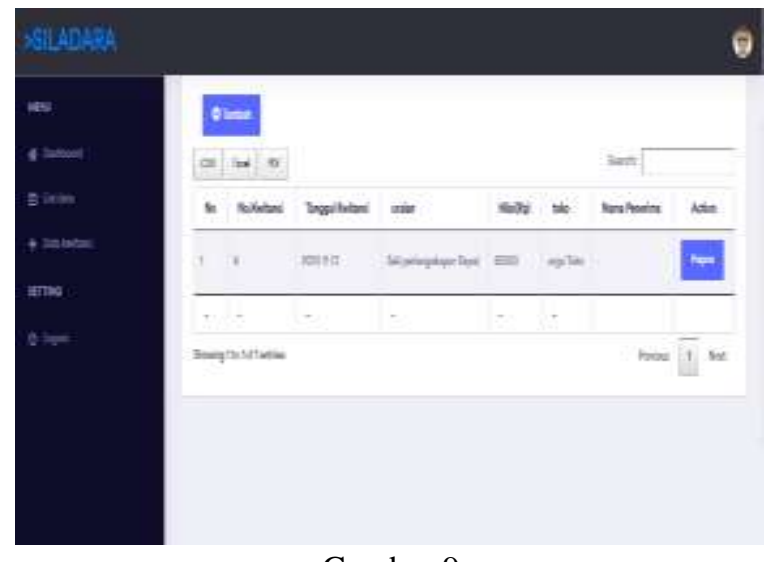

Gambar 9

Halaman Data Kwitansi

\section{KESIMPULAN}

\subsection{Kesimpulan}

Berdasarkan hasil penelitian dan pengujian terhadap sistem Laporan daya serap yang telah dirancang dan dibangun.Dapat disimpulkan bahwa sistem ini merupakan salah satu solusi dalam mempermudah penulisan laporan di bagian anggaran dan data kwitansi BPS Kabupaten Sukabumi. Sistem ini berbasis web sehingga mudah di gunakan dan hanya membutuhkan jaringan internet untuk mengaksesnya.

\subsection{Saran}

Sistem yang dibangun masih berbentuk prototype atau uji coba. Oleh karena itu ada beberapa hal yang harus dikembangkan agar sistem ini bisa digunakan sepenuhnya, antara lain:

1. Diharapkan dalam pengembangan selanjutnya sistem ini sudah bisa digunakan secara online atau tanpa menggunakan localhost.

2. Pengembangan dalam sistem laporan daya serap basis web ini diharapkan dapat digunakan selain sebagai penyimpanan dan input data, tetapi bisa juga digunakan dalam perhitungan total anggaran dan jumlah kwitansi.

\section{UCAPAN TERIMA KASIH}

Penulis mengucapkan terima kasih kepada semua pihak yang telah membantu penulis dalam menyelesaikan penelitian ini secara langsung maupun tidak langsung. Tidak lupa juga penulis ucapkan terima kasih banyak kepada intansi BPS Kabupaten Sukabumi terutama di bagian Staff $\mathrm{Tu}$, atas informasi dan kerja samanya selama penelitian ini berlangsung.

\section{DAFTAR PUSTAKA}

[1] Sibero, Alexander F. K. 2013. Web Programming Power Pack. Yogyakarta: Lokomedia.

[2] Sadeli, Muhammad. 2014. Aplikasi Bisnis dengan PHP \& MYSQL. Palembang:Maxikom

[3] Sibero, Alexander F. K. 2011. Kitab Suci Web Programming. MediaKom.

[4] Dimas, Setiawan. 2019. "Pengertian Codeigniter dan Konsep MVC (Model, View, Controller)". http://Kelasprogrammer.com/pengertian- codeigniterKonsep-mvc (diakses tanggal 29 Desember 2020)

[5] Achmad Yusron Arif. 2019."Pengertian MySQL, Kelebihan Dan Kekurangan.” 2019: 1-7.

[6] "RANCANG BANGUN LAYANAN WEB (WEB SERVICE) UNTUK APLIKASI REKAM MEDIS PRAKTIK PRIBADI DOKTER.”2017. Jurnal karya Ilmiah Teknik Elektro 2 (1): 1-8.

[7] Sulistyorini, P. 2009. "Pemodelan Visual dengan Menggunakan UML dan Rational Rose."Jurnal Teknologi Informasi DINAMIK, 14(1). 23-29. 
[8] Somya, R. dan Nathanael, T. M. E. 2019.” Pengembangan Sistem Informasi Pelatihan Berbasis Web Menggunakan Teknologi Web Service Dan Framework Laravel."Jurnal TECHNO Nusa Mandiri 16 (1). PPPM STMIK Nusa Mandiri: 51 - 58.

[9] Pressman, R. 2010. Software Engineering: A Practitioner's Approach. Seventh Edition.

[10] Purnomo, R., dan Beeh, Y. R. 2016. "Perancangan Aplikasi Emergency Button Berbasis Android."Universitas Universitas Krist: 1-23. 